\title{
The effect of aprepitant for the prevention of postoperative nausea and vomiting in patients undergoing gynecologic surgery with intravenous patient controlled analgesia using fentanyl: aprepitant plus ramosetron vs ramosetron alone
}

\author{
Se-Jin Lee, Su Myung Lee, Soon Im Kim, Si Young Ok, Sang Ho Kim, Sun-Young Park, and Mun-Gyu Kim
}

Department of Anesthesiology and Pain Medicine, Soonchunhyang University Seoul Hospital, Seoul, Korea

Background: The purpose of this study was to evaluate the effect of an aprepitant, neurokinin-1(NK1) receptor antagonist, for reducing postoperative nausea and vomiting (PONV) for up to 24 hours in patients regarded as high risk undergoing gynecological surgery with intravenous patient-controlled analgesia (IV PCA) using fentanyl.

Methods: In this randomized, open label, case-control study 84 gynecological surgical patients receiving a standardized general anesthesia were investigated. Patients were randomly allocated to receive aprepitant $80 \mathrm{mg}$ P.O. approximately $2-3$ hours before operation (aprepitant group) or none (control group). All patients received ramosetron $0.3 \mathrm{mg}$ IV after induction of anesthesia. The incidence of PONV, severity of nausea, and use of rescue antiemetics were evaluated for up to 24 hours postoperatively.

Results: The incidence of nausea was significantly lower in the aprepitant group (50.0\%) compared to the control group (80.9\%) during the first 24 hours following surgery. The incidence of vomiting was significantly lower in the aprepitant group (4.7\%) compared to the control group (42.8\%) during the first 24 hours following surgery. In addition, the severity of nausea was less among those in the aprepitant group compared with the control group over a period of 24 hours post-surgery $(\mathrm{P}<0.05)$. Use of rescue antiemetics was lower in the aprepitant group than in the control group during 24 hours postoperatively $(\mathrm{P}<0.05)$.

Conclusions: In patients regarded as high risk undergoing gynecological surgery with IV PCA using fentanyl, the aprepitant plus ramosetron ware more effective than ramosetron alone to decrease the incidence of PONV, use of rescue antiemetics and nausea severity for up to 24 hours postoperatively. (Korean J Anesthesiol 2012; 63: 221-226)

Key Words: Aprepitant, Gynecologic anesthesia, Neurokinin-1 receptor, Patient controlled analgesia, Postoperative nausea and vomiting, Ramosetron.

Received: February 23, 2012. Revised: 1st, April 1, 2012; 2nd, April 17, 2012. Accepted: April 18, 2012.

Corresponding author: Soon Im Kim, M.D., Ph.D., Department of Anesthesiology and Pain Medicine, Soonchunhyang University Seoul Hospital, 22, Daesagwan-gil, Yongsan-gu, Seoul 140-887, Korea. Tel: 82-2-705-9294, Fax: 82-2-790-0394, E-mail: soonnim@schmc.ac.kr (c) This is an open-access article distributed under the terms of the Creative Commons Attribution Non-Commercial License (http:// creativecommons.org/licenses/by-nc/3.0/), which permits unrestricted non-commercial use, distribution, and reproduction in any medium, provided the original work is properly cited. 


\section{Introduction}

Nausea and vomiting are the most common complaints by patients after anesthesia. The phenomenon known as postoperative nausea and vomiting (PONV) has generated as much interest as post-operative pain experienced by patients [1]. PONV may occur after the onset of postoperative complications, including symptoms such as discomfort, pain, dehydration, electrolyte imbalance, surgical wound dehiscence, hemorrhage, and aspiration pneumonia [2]. The prevalence rate of PONV is about $30 \%$, but it however this rate fluctuates according to each patient, plus surgical and anesthetic factors. It may be as great as $80 \%$ or higher in patients with high-risk for PONV $[3,4]$. The Neurokinin-1 (NK1) receptors which exist in the gastrointestinal vagal afferent and central nervous system vomiting reflex pathway generate conditions of nausea and vomiting due to activation by Substance $\mathrm{P}$ [5].

Aprepitant is a selective NK1 receptor antagonist. This antiemetic was approved for use by the FDA in 2003. Aprepitant has long half-life and has demonstrated efficacy against nausea and vomiting according to studies focused on chemotherapy (chemotherapy induced nausea and vomiting, CINV) in combination other antiemetic drugs [6]. Also it has been reported to be effective in PONV prevention and was superior to ondansetron, particularly with regards to the antiemetic effect $[7,8]$. However, there is currently no research report about aprepitant use in PONV prevention among the Korean population.

Therefore, the aim of this research was to determine the efficacy of PONV prevention with aprepitant and subsequently compare the use of the aprepitant with ramosetron and ramosetron single injection in patients who were considered at high risk for PONV, gynecologic surgery receiving IV PCA using fentanyl in general anesthesia.

\section{Materials and Methods}

This research was carried out between April 10th and November 30th in 2011. After we obtained permission from the Institutional Review Board, we explained the details of this study and received written informed consent from all patients.

Eligible patients included 84 women between 20 and 70 years of age, with a physical status of I-II according to the American Society of Anesthesiologists, who were scheduled to undergo gynecological surgery with general anesthesia and received IV PCA.

Exclusion criteria included patient refusal to participate in the research, patients who had a history of drug abuse, hypersensitivity reaction, nausea and received antiemetics before surgery within 24 hours, pregnancy, breastfeeding status, cancer patients, inadequate participation in clinical trials due to other reasons.

According to computer-based random number generation, patients were divided into an aprepitant group $(n=42)$ and a control group $(n=42)$. Those in the aprepitant group were administered $80 \mathrm{mg}$ aprepitant (Emend [R], Seoul, Korea, MSD) orally $2-3$ hours before induction of anesthesia while the control group did not receive administration of any drug.

All patients received $0.2 \mathrm{mg}$ glycopyrrolate IM as premedication 30 mins before the operation and when arriving at the operating room, standardized monitoring was initiated to include noninvasive blood pressure measuring equipment, electrocardiogram, and pulse oximeter.

Patients were induced with $2 \mathrm{mg} / \mathrm{kg}$ propofol intravenously. After the loss of consciousness, desflurane was used to maintain anesthesia that allowed for sufficient muscle relaxation using 0.6 $\mathrm{mg} / \mathrm{kg}$ rocuronium implemented by endotracheal intubation.

In all patients, the ramosetron $0.3 \mathrm{mg}$ (Nasea ${ }^{\circledR}$, Astellas Pharma Korea Inc., Seoul, Korea) was administered intravenously after induction of anesthesia.

The maintenance of anesthesia was performed with $2 \mathrm{~L} / \mathrm{min}$ $\mathrm{O}_{2}$ and $\mathrm{N}_{2} \mathrm{O}, 6-8$ vol\% desflurane, and $0.1-0.3 \mathrm{mcg} / \mathrm{kg} / \mathrm{min}$ remifentanil. Additional doses of rocuronium were given when further muscle relaxation was necessary.

The end tidal partial pressure of carbon dioxide was maintained between 35 and $40 \mathrm{mmHg}$.

After the surgery, muscle relaxation was reversed by administering pyridostigmine and glycopyrrolate.

For postoperative pain control, IV patient controlled analgesia was used so that $1,500 \mathrm{mcg}$ fentanyl was diluted with $70 \mathrm{ml}$ saline solution and it was administered at a basic basal infusion rate of $1 \mathrm{ml} / \mathrm{h}$, bolus $1 \mathrm{ml}$, and lockout time 6 minute.

In cases where nausea and vomiting were serious or the patient desired the treatment, $10 \mathrm{mg}$ metoclopramide was administered. When necessary, $4 \mathrm{mg}$ ondansetron was administrated as an additional treatment.

Table 1. Patient Characteristics

\begin{tabular}{lcc}
\hline & $\begin{array}{c}\text { Control group } \\
(\mathrm{n}=42)\end{array}$ & $\begin{array}{c}\text { Aprepitant group } \\
(\mathrm{n}=42)\end{array}$ \\
\hline Age (yr) & $43.6 \pm 10.4$ & $43.8 \pm 8.2$ \\
Weight (kg) & $61.3 \pm 12.1$ & $61.2 \pm 8.8$ \\
Duration of operation (min) & $124.1 \pm 48.7$ & $113.4 \pm 61.6$ \\
Duration of anesthesia (min) & $158.8 \pm 48.9$ & $145.0 \pm 62.3$ \\
History of PONV (n) & 3 & 2 \\
History of motion sickness (n) & 8 & 6 \\
Smoking (n) & 3 & 2 \\
Intraoperative remifentanil & $247.2 \pm 62.5$ & $332.79 \pm 61.2$ \\
dose (mcg) & & \\
\hline
\end{tabular}

Values are mean \pm SD or number of patients. PONV: postoperative nausea and vomiting. There are no significant differences between the groups. 
The patient's age, weight, surgery time, anesthesia time, past history of nausea, past history of PONV, smoking and amount of usage of remifentanil was recorded. There was no statistically significant difference between the two groups (Table 1).

In the recovery room, the anesthesiologist visited with each patient, being blinded to the conditions. The incidence of PONV, severity of nausea, use of rescue antiemetics, along with side effect such as dizziness and headache were evaluated.

The extent of nausea was assessed by a 5-point Verbal Rating Scale (VRS), in which patients rated nausea from none to intractable (none: no nausea, mild : mild nausea, moderate: moderate nausea, severe: severe nausea, and intractable: intolerable as well as vomiting).

PONV incidence was looked at in 5-hydroxytryptamine type 3 (5-HT3) receptor antagonist single injection at approximately $70 \%[9,10]$, the absolute reduction rate was expected at $30 \%$ and the group per 42 people found the number of valid sample with aprepitant administration in the significance level of the power of $80 \%$ and with an alpha value of 0.05 .

Table 2. Incidence of Postoperative Nausea and Vomiting (PONV)

\begin{tabular}{lccr}
\hline & $\begin{array}{c}\text { Control group } \\
(\mathrm{n}=42)\end{array}$ & $\begin{array}{c}\text { Aprepitant group } \\
(\mathrm{n}=42)\end{array}$ & P value \\
\hline $0-6 \mathrm{hr}$ & & $18(42.8)$ & 0.016 \\
Nausea & $29(69.0)$ & $1(2.4)$ & 0.002 \\
Vomiting & $11(26.2)$ & & \\
6-24 hr & & $13(31.0)$ & 0.046 \\
Nausea & $22(52.4)$ & $1(2.4)$ & 0.001 \\
Vomiting & $12(28.6)$ & & 0.005 \\
$0-24$ hr & $34(80.9)$ & $21(50.0)$ & $<0.001$ \\
Nausea & $18(42.8)$ & $22(52.4)$ & 0.005 \\
Vomiting & $34(80.9)$ & & \\
Total PONV & & & \\
\hline
\end{tabular}

Values are number of patients (\%). PONV: postoperative nausea and vomiting.

Table 3. Severity of Postoperative Nausea Using 5-point VRS

\begin{tabular}{llccc}
\hline & & $\begin{array}{c}\text { Control } \\
\text { group } \\
(\mathrm{n}=42)\end{array}$ & $\begin{array}{c}\text { Aprepitant } \\
\text { group } \\
(\mathrm{n}=42)\end{array}$ & P value \\
\hline $0-6 \mathrm{hr}$ & None & $13(30.9)$ & $24(57.1)$ & \\
& Mild & $7(16.6)$ & $8(19.0)$ & \multirow{6}{*}{0.002} \\
& Moderate & $5(11.9)$ & $4(9.5)$ & \\
& Severe & $10(23.8)$ & $5(11.9)$ & \\
& Intractable & $7(16.6)$ & $1(2.3)$ & \\
& None & $20(47.6)$ & $29(69.0)$ & \\
& Mild & $6(14.2)$ & $3(7.1)$ & \\
& Moderate & $3(7.1)$ & $5(11.9)$ & 0.002 \\
& Severe & $8(19.0)$ & $4(9.5)$ & \\
& Intractable & $5(11.9)$ & $1(2.3)$ &
\end{tabular}

Values are number of patients (\%). 5-point VRS; None: no nausea, Mild: Mild nausea, Moderate: moderate nausea, Severe: severe nausea, Intractable: nausea as bad as it could be.
Analysis of data was performed using SPSS 14.0 (SPSS Inc., Chicago, IL., USA). The categorical data was analyze using the chi-square test and continuous data along with the Student's t-test.

In all analyses, statistical significance was set at $\mathrm{P}<0.05$.

\section{Results}

The incidence of PONV was significantly lower in the aprepitant group (52.4\%) compared to the control group (80.9\%) during the first 24 hours following surgery $(\mathrm{P}<0.05)$ (Table 2).

The incidence of nausea was significantly lower in the aprepitant group (50.0\%) compared to the control group (80.9\%) during the first 24 hours following surgery, and there were significant differences in the incidence of vomiting between the two groups, evidenced by $42.8 \%$ in the control group and $4.7 \%$ in the aprepitant group $(\mathrm{P}<0.05)$ (Table 2).

The incidence of nausea was significantly lower among those within the aprepitant group (42.8\%) relative to the control group (69.0\%) during the first 6 hours following surgery, and the incidence of nausea was significantly lower in the aprepitant group (31.0\%) compared to the control group (52.4\%) during the 6-24 hours following surgery. There were significant differences in the incidence of vomiting between the two groups with $26.2 \%$ in the control group and $2.4 \%$ in the aprepitant group during the first 6 hours following surgery, and $28.6 \%$ in the control group and $2.4 \%$ in the aprepitant group during 6-24 hours following surgery $(\mathrm{P}<0.05)$ (Table 2$)$.

In addition, severity of nausea was less in the aprepitant group as compared with the control group $(\mathrm{P}<0.05)$ (Table 3$)$.

Use of rescue antiemetics was lower in the aprepitant group $(28.5 \%)$ than in the control group (52.3\%) for 24 hours postoperatively $(\mathrm{P}<0.05)$ (Table 4$)$.

Table 4. Use of Rescue Antiemetics

\begin{tabular}{lccl}
\hline & $\begin{array}{c}\text { Control group } \\
(\mathrm{n}=42)\end{array}$ & $\begin{array}{c}\text { Aprepitant group } \\
(\mathrm{n}=42)\end{array}$ & P value \\
\hline $0-6 \mathrm{hr}$ & $20(47.6)$ & $9(21.4)$ & 0.012 \\
$6-24 \mathrm{hr}$ & $13(31.0)$ & $5(11.9)$ & 0.033 \\
$0-24 \mathrm{hr}$ & $22(52.3)$ & $12(28.5)$ & 0.026 \\
\hline
\end{tabular}

Values are number of patients (\%).

Table 5. Incidences of Adverse Events

\begin{tabular}{lccc}
\hline & $\begin{array}{c}\text { Control group } \\
(\mathrm{n}=42)\end{array}$ & $\begin{array}{c}\text { Aprepitant group } \\
(\mathrm{n}=42)\end{array}$ & P value \\
\hline Dizziness & $10(23.8)$ & $8(19.0)$ & 0.595 \\
Headache & $6(14.3)$ & $5(11.9)$ & 0.746 \\
Sedation & $2(4.8)$ & $1(2.4)$ & 0.557 \\
\hline
\end{tabular}

Values are number of patients (\%). 
There were no differences in the incidence of dizziness between the two groups as $23.8 \%$ in the control group and $19.0 \%$ in the aprepitant group were observed during 24 hours following surgery, and there were no differences in the incidence of headache between the two groups with $14.3 \%$ in the control group and $11.9 \%$ in the aprepitant group, and there were no differences in the incidence of sedation between the two groups as we observed $4.8 \%$ in the control group and $2.4 \%$ in the aprepitant group (Table 5).

\section{Discussion}

In this study, results demonstrated that the use of combination therapy of $80 \mathrm{mg}$ aprepitant oral administration and IV $0.3 \mathrm{mg}$ ramosetron was lower in the incidence of nausea and vomiting than IV $0.3 \mathrm{mg}$ ramosetron alone, particularly when the incidence of vomiting was expected to be markedly reduced.

Considering the patient's discomfort and a high incidence of PONV, many new drugs for prevention and treatment of PONV were developed and studied recently but there is no drug which fully prevents and effectively treats PONV $[2,11]$.

Factors of nausea and vomiting after surgery are varied including patient's individual factors, surgical factors and anesthetic factors. Patient's individual factors in women include young age, obesity, past history of nausea and vomiting, motion sickness and surgical factors is otorhinolaryngologic surgery, breast surgery, strabismus surgery, gynecological surgery, and laparoscopic surgery while anesthetic factors include volatile anesthetics, nitrous oxide, narcotic analgesics, and long duration of aesthesia.

Among various predictors of PONV, Apfel et al. [3] described that independent predictive factors include gender, history of the motion sickness or PONV, lack of smoking habits and use of opioids after surgery. And if none, one, two, three, or four of these risk factors were present, the incidences of PONV were 10, $21,39,61$, and $79 \%$, respectively.

All patients in this study were considered high-risk with more than a rated 3 risk factor, including female gender, use of opioid for pain control, gynecological surgery and least $90 \%$ of patients were non-smokers.

In the past, the droperidol and selective 5-HT3 receptor antagonists were most commonly used for PONV [12]. However, after the United States Food and Drug Administration warned that use of droperidol can cause serious arrhythmia in 2001, droperidol use is controversial and its production was interrupted in Korea $[13,14]$. Subsequently, serotonin receptor antagonists have been widely used for the prevention and treatment of PONV and CINV because there is low risk of side effects as compared with other antiemetics [12]. However, the incidence of PONV was reported as high as $30-40 \%$ in spite of this prevention and treatment.

In our observations, the incidence of PONV was higher than our expectation as $\mathbf{8 0 \%}$ was seen in the control group which received ramosetron alone during 24 hours postoperatively.

However, Oh et al. [9] have shown that incidence of PONV was high as $67 \%$ in patients who were administered a ramosetron single injection under laparoscopic operation during the first 12 hours after surgery. Kim et al. [10] showed that the incidence of PONV was each $70.7 \%$ and $66.7 \%$ in the patients who were administered other serotonin antagonists such as ondansetron, dolasetron receiving IV PCA after mastectomy during the first 24 hours postoperatively.

Even with administration of ramosetron, the incidence of PONV has been high. This may be due to the influence of nitrous oxide in combination with remifentanil. Thus, we were able to determine that the patients who received IV-PCA using opioids in the high risk group of PONV needed combination therapy with other several antiemetic drugs rather than the antiemetic drug single injection through our study.

Henzi et al. [15] found that the combination of serotonin receptor antagonist with dexamethasone decreased the risk of PONV, and Khalil et al. [16] found that the combination of serotonin receptor antagonist with promethazine decreased the incidence and severity of PONV.

Aprepitant has been involved in numerous studies in the area of CINV, there are currently many studies that have reported on aprepitant use for PONV $[8,17]$. Antiemetic effect of aprepitant results from blocking the binding of substance $P$ which is known to be related to delayed vomiting at the NK1 receptor [18]. The NK1 receptor antagonist was shown to act in both the central nervous system and peripheral nervous system [19-21].

However, there has not yet been a study for domestic patients, and this study will be used as a starting point in the clinical application of aprepitant, as it focused in particular on high-risk patients of PONV with gynecologic patients.

Diemunsch et al. [22] stated that the efficacy of aprepitant was superior to ondansetron. Gan et al. [7] stated that aprepitant and ondansetron are similar in their effect on nausea reduction, but prevention of vomiting of aprepitant was better than that of ondansetron in the study comparing aprepitant versus ondansetron. Recently, Vallejo et al. [23] stated that the addition of aprepitant to ondansetron significantly decreased postoperative vomiting rates and nausea severity for up to 48 hours postoperatively, in patients undergoing plastic surgery.

We observed that the incidence of nausea was reduced statistically significantly by $50 \%$ in the aprepitant group compared to $80.9 \%$ in the control group and the incidence of vomiting reduced significantly to $4.7 \%$ in aprepitant group compared to $42.8 \%$ in the control group for 24 hours. Relative 
reduction rate of nausea was $38 \%$ whereas relative reduction rate of vomiting was $89 \%$. This suggests that anti-vomiting effect is excellent compared with the anti-nausea effect of aprepitant. This result is similar to those found in a previous study with a $80 \%$ relative reduction rate of vomiting with a novel, neurokonin-1 antagonist, cp-122,721, compared to placebo, as reported by Gesztesi et al. [24].

The strong anti-vomiting effect of aprepitant is very useful when vomiting occurs and creates dangerous complications, such as in neurosurgery or jaw-wiring incidents.

Gan et al. [7] stated that the aprepitant was more effective than ondansetron in vomiting prevention but it did not show any difference between $40 \mathrm{mg}$ and $125 \mathrm{mg}$ in terms of the dose of the aprepitant in the study, while Kakuta et al. [17] suggested that aprepitant can effectively lower PONV and also hasten recovery in gynecological laparoscopic surgery comparing aprepitant $80 \mathrm{mg}$ with placebo.

In addition, the aprepitant $80 \mathrm{mg}$ was used in this research because the product on the market in Korea was only available in 2 doses, $80 \mathrm{mg}$ and $120 \mathrm{mg}$.

Headache, dizziness are the most common known side effects of selective 5-HT3 receptor antagonists.

In our research, 8 patients (19\%) in the aprepitant group and 10 patients $(23.8 \%)$ in the control group experienced dizziness and headache occurred in 6 patients (14.3\%) in the control group and 5 patients (11.9\%) in aprepitant group but because there was no difference between 2 groups statistically, the headache did not seem to affect the overall clinical conditions of the patients.

Limitations of this study included the fact that placebo and aprepitant groups could not be directly compared. However, as there was an ethical issue as all patients of within the study were high-risk subjects, ramosetron was administered to all patients within both groups.

In conclusion, in patients regarded as high risk undergoing gynecological surgery with IV PCA using fentanyl, $80 \mathrm{mg}$ aprepitant plus $0.3 \mathrm{mg}$ ramosetron reduced the incidence of PONV, use of rescue antiemetics and nausea severity as compared to $0.3 \mathrm{mg}$ ramosetron alone for up to 24 hours postoperatively to be significant.

Further research is needed to compare the efficacy of serotonin receptor antagonists and aprepitant as well as the combination of other antiemetic drugs in the prevention and treatment of PONV.

\section{References}

1. Eberhart LH, Morin AM, Wulf H, Geldner G. Patient preferences for immediate postoperative recovery. Br J Anaesth 2002; 89: 760-1.

2. Gan TJ. Risk factors for postoperative nausea and vomiting. Anesth
Analg 2006; 102: 1884-98.

3. Apfel CC, Laara E, Koivuranta M, Greim CA, Roewer N. A simplified risk score for predicting postoperative nausea and vomiting: conclusions from cross-validations between two centers. Anesthesiology 1999; 91: 693-700.

4. Cohen MM, Duncan PG, DeBoer DP, Tweed WA. The postoperative interview: assessing risk factors for nausea and vomiting. Anesth Analg 1994; 78: 7-16.

5. Leslie RA. Neuroactive substances in the dorsal vagal complex of the medulla oblongata: nucleus of the tractus solitarius, area postrema, and dorsal motor nucleus of the vagus. Neurochem Int 1985; 7 : 191-211.

6. Longo F, Mansueto G, Lapadula V, De Sanctis R, Quadrini S, Grande $\mathrm{R}$, et al. Palonosetron plus 3-day aprepitant and dexamethasone to prevent nausea and vomiting in patients receiving highly emetogenic chemotherapy. Support Care Cancer 2011; 19: 1159-64.

7. Gan TJ, Apfel CC, Kovac A, Philip BK, Singla N, Minkowitz H, et al. A randomized, double-blind comparison of the NK1 antagonist, aprepitant, versus ondansetron for the prevention of postoperative nausea and vomiting. Anesth Analg 2007; 104: 1082-9.

8. Diemunsch P, Joshi GP, Brichant JF. Neurokinin-1 receptor antagonists in the prevention of postoperative nausea and vomiting. Br J Anaesth 2009; 103: 7-13.

9. Oh DS, Lee JH, Lee SE, Kim YH, Lim SH, Lee KM, et al. Comparison of ramosetron plus dexamethasone with ramosetron alone in the prevention of nausea and vomiting after gynecologic laparoscopic surgery. Korean J Anesthesiol 2009; 56: 169-74.

10. Kim MS, Lee SY, KIM JS, Min SK, Park YD, Park HJ. The effect of ondansetron or dolasetron for the prevention of postoperative nausea and vomiting in patients with intravenous patient-controlled analgesia. Korean J Anesthesiol 2007; 53: 624-9.

11. Apfel CC, Korttila K, Abdalla M, Kerger H, Turan A, Vedder I, et al. A factorial trial of six interventions for the prevention of postoperative nausea and vomiting. N Engl J Med 2004; 350: 2441-51.

12. Gan TJ, Meyer T, Apfel CC, Chung F, Davis PJ, Eubanks S, et al. Consensus guidelines for managing postoperative nausea and vomiting. Anesth Analg 2003; 97: 62-71.

13. Bailey P, Norton R, Karan S. The FDA droperidol warning: is it justified? Anesthesiology 2002; 97: 288-9.

14. Dershwitz M. There should be a threshold dose for the FDA blackbox warning on droperidol. Anesth Analg 2003; 97: 1542-3.

15. Henzi I, Walder B, Tramèr MR. Dexamethasone for the prevention of postoperative nausea and vomiting: a quantitative systematic review. Anesth Analg 2000; 90: 186-94.

16. Khalil S, Philbrook L, Rabb M, Wells L, Aves T, Villanueva G, et al. Ondansetron/promethazine combination or promethazine alone reduces nausea and vomiting after middle ear surgery. J Clin Anesth 1999; 11: 596-600.

17. Kakuta N, Tsutsumi YM, Horikawa YT, Kawano H, Kinoshita M, Tanaka K, et al. Neurokinin-1 receptor antagonism, aprepitant, effectively diminishes post-operative nausea and vomiting while increasing analgesic tolerance in laparoscopic gynecological procedures. J Med Invest 2011; 58: 246-51.

18. Andrews PL, Sanger GJ. Abdominal vagal afferent neurones: an important target for the treatment of gastrointestinal dysfunction. Curr Opin Pharmacol 2002; 2: 650-6. 
19. Tattersall F, Rycroft W, Cumberbatch M, Mason G, Tye S, Williamson DJ, et al. The novel NK1 receptor antagonist MK-0869 (L-754,030) and its water soluble phosphoryl prodrug, L-758,298, inhibit acute and delayed cisplatin-induced emesis in ferrets. Neuropharmacology 2000; 39: 652-63.

20. Tattersall F, Rycroft W, Hill R, Hargreaves RJ. Enantioselective inhibition of ampomorphine-induced emesis in the ferret by the neurokinin1 receptor antagonist CP-99,994. Neuropharmacology 1994; 33: 259-60.

21. Tattersall FD, Rycroft W, Francis B, Pearce D, Merchant K, MacLeod AM, et al. Tachykinin NK1 receptor antagonists act centrally to inhibit emesis induced by the chemotherapeutic agent cisplatin in ferrets. Neuropharmacology 1996; 35: 1121-9.
22. Diemunsch P, Apfel C, Gan TJ, Candiotti K, Philip BK, Chelly J, et al. Preventing postoperative nausea and vomiting: post hoc analysis of pooled data from two randomized active-controlled trials of aprepitant. Curr Med Res Opin 2007; 23: 2559-65.

23. Vallejo MC, Phelps AL, Ibinson JW, Barnes LR, Milord PJ, Romeo $\mathrm{RC}$, et al. Aprepitant plus ondansetron compared to ondansetron alone in reducing postoperative nausea and vomiting in ambulatory patients undergoing plastic surgery. Plast Reconstr Surg 2012; 129: 519-26.

24. Gesztesi Z, Scuderi PE, White PF, Wright W, Wender RH, D'Angelo R, et al. Substance $P$ (Neurokinin-1) antagonist prevents postoperative vomiting after abdominal hysterectomy procedures. Anesthesiology 2000; 93: 931-7. 